$03,13,19$

\title{
Исследования термоэлектрических свойств сверхрешеток на основе силицида марганца и германия
}

\author{
() М.В. Дорохин, Ю.М. Кузнецов, В.П. Лесников, А.В. Здоровейщев, П.Б. Дёмина, И.В. Ерофеева \\ Научно-исследовательский физико-технический институт \\ Нижегородского государственного университета им. Н.И. Лобачевского, \\ Нижний Новгород, Россия \\ E-mail: dorokhin@nifti.unn.ru
}

Поступила в Редакцию 16 июля 2019 г.

В окончательной редакции 16 июля 2019 г.

Принята к публикации 25 июля 2019 г.

\begin{abstract}
Представлены результаты исследования термоэлектрических материалов, сформированных методом импульсного лазерного осаждения на подложках сапфира и представляющих собой тонкие пленки $\mathrm{MnSi}_{1.74} \mathrm{c}$ промежуточными слоями германия. В работе показано резкое снижение коэффициента теплопроводности сверхрешеток на основе силицида марганца и германия по сравнению с одиночными слоями силицида марганца эквивалентной толщины, что позволяет в разы повысить коэффициент термоэлектрической эффективности. Полученные значения коэффициента термоэлектрической добротности сопоставимы с известными из литературы значениями, характерные для аналогичных структур.
\end{abstract}

Ключевые слова: тонкие пленки, высший силицид марганца, сверхрешетки, термоэлектрический эффект Зеебека, термоэлектрическая добротность.

DOI: $10.21883 /$ FTT.2019.12.48550.56ks

\section{1. Введение}

В виду экологических проблем, связанных с работой современных технологичных методов выработки электрической энергии, ведется активная разработка альтернативных источников энергии, принцип действия которых не приносит вреда окружающей среде. Солнечные батареи, бетавольтаика, водородные ячейки, водородное топливо - лишь небольшой список направления разработок поиска экологически чистого метода генерации электрической энергии [1]. Одним из перспективных направлений исследования является разработка термоэлектрических преобразователей энергии. Термоэлектрики - материалы, вырабатывающие электрическое напряжения при создании градиента температур на противоположных гранях.

Основным параметром, характеризующим коэффициент полезного действия (КПД) будущего термоэлектрического преобразователя энергии является безразмерный параметр термоэлектрической добротности $Z T=\alpha^{2} T / \rho \lambda$, где $\lambda-$ коэффициент теплопроводности, $\sigma$ - электропроводность, $\alpha-$ коэффициент Зеебека, $T$ - средняя температура структуры.

Для достижения высоких параметров термоэлектрической добротности $(Z T \approx 1-3)$ необходимо разработать материал с высоким коэффициентом электропроводности и низким коэффициентом теплопроводности. Оптимальное соотношение параметров достигается в сильнолегированных полупроводниках, однако для объемных полупроводниковых материалов известно ограниченное число публикаций, в которых сообщалось бы о получении $Z T$ больше 1 [2,3]. Поскольку коэффициент $Z T$ напрямую связан с КПД, низкие характерные значения ZT не позволяют, в большинстве случаев, получить материал, конкурентоспособный по сравнению с другими способами производства электрической энергии. Более того, тепловые и электрические параметры, входящие в формулу для $Z T$, зависят друг от друга в одном материале: при увеличении электропроводности наблюдается рост коэффициента теплопроводности за счет увеличения вклада переноса тепла свободными носителями заряда и уменьшение коэффициента Зеебека за счет изменения положения уровня Ферми (вглубь зоны проводимости или валентной зоны в зависимости от типа проводимости материала).

Значительный сегмент современных исследований по тематике [4-9] направлен на разработку термоэлектриков на основе химических соединений со сложной кристаллической структурой, состоящей из двух сортов значительно различающихся по размеру атомов (например,

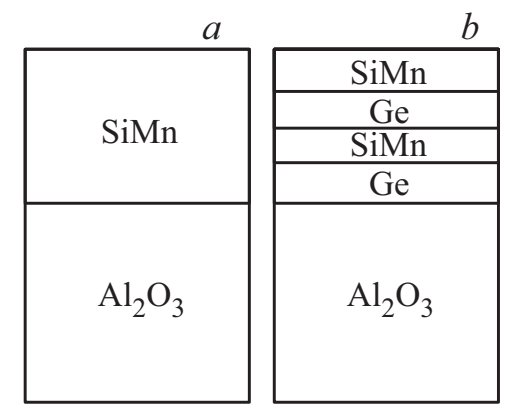

Рис. 1. Принципиальная схема исследуемых структур: $a-$ одиночный слой ВСМ, $b-$ сверхрешетка из слоев ВСМ и германия. 
Параметры полученных искровым спеканием образцов

\begin{tabular}{|c|c|c|c|c|}
\hline Название & Мишени & $\begin{array}{c}\text { Состав } \\
\text { структуры }\end{array}$ & $\begin{array}{c}\text { Время распыления } \\
\text { мишеней, min }\end{array}$ & $\begin{array}{c}\text { Толщина } \\
\text { структуры, } \mathrm{nm}\end{array}$ \\
\hline Struct 1 & $1-\mathrm{SPSM}$ & $\mathrm{MnSi}_{1.7}$ & PSM $15-73^{\prime}$ & 50 \\
\hline Struct 2 & $\begin{array}{l}1-\text { SPSM } 15 \\
2-\text { Ge- } 0.005\end{array}$ & {$\left[\mathrm{MnSi}_{1.7} / \mathrm{Ge}\right]_{6}$} & $\begin{array}{l}\text { SPSM } 15-6^{\prime} \\
\quad \text { Ge }-6^{\prime}\end{array}$ & 30 \\
\hline Struct 3 & $\begin{array}{l}1-\text { SPSM } 15 \\
2-\text { Ge- } 0.005\end{array}$ & {$\left[\mathrm{MnSi}_{1.7} / \mathrm{Ge}\right]_{6}$} & $\begin{array}{l}\text { SPSM } 15-9^{\prime} \\
\quad \text { Ge }-3^{\prime}\end{array}$ & 50 \\
\hline Struct 4 & $\begin{array}{l}1-\text { SPSM } 15 \\
2-\text { Ge- } 0.005\end{array}$ & {$\left[\mathrm{MnSi}_{1.7} / \mathrm{Ge}\right]_{12}$} & $\begin{array}{l}\text { SPSM } 15-3^{\prime} \\
\quad \text { Ge }-3^{\prime}\end{array}$ & 50 \\
\hline
\end{tabular}

высший силицид марганца). За счет применения такого подхода возможно достичь рассогласования фононных спектров с целью снижения фононной составляющей коэффициента теплопроводности [4]. Создание сверхрешеток, содержащих подобные материалы и промежуточные слои, обеспечивающие дополнительное рассеяние фононов на гетерограницах. Подобный подход позволяет еще более значительно уменьшить коэффициент теплопроводности [10-11].

Настоящая работа посвящена исследованию термоэлектрических свойств наноразмерных пленок, представляющих собой одиночные и многослойные структуры, состоящие из соединения силицида марганца по составу близкого к высшему силициду марганца (BCM) $\mathrm{MnSi}_{1.74}$ (рис. $1, a)$ и промежуточных слоев германия (рис. $1, b)$.

\section{2. Методика формирования структур}

Пленки формировались методом импульсного лазерного осаждения (ИЛО) в вакууме. В качестве мишеней выступали пластина германия марки ГДГ-0005 и мишень высшего силицида марганца, спеченная из нанопорошков методом электроимпульсного плазменного спекания (ЭИПС) [12]. Использование в качестве мишени заранее спеченного материала нужного состава позволяет получить пленки с зафиксированной концентрацией марганца.

Мишени распылялись импульсным $\mathrm{Nd}: \mathrm{YAG}$ лазеров, работающим в режиме модулированной добротности. Распыляемый материал осаждался на сапфировую подложку, температура которой составляла $350^{\circ} \mathrm{C}$. При осаждении однородной $\mathrm{MnSi}_{1.74}$ пленки мишень высшего силицида марганца распылялась непрерывно в течение всего процесса осаждения ( $40 \mathrm{~min})$. При осаждении многослойной структуры $\mathrm{MnSi}_{1.74} / \mathrm{Ge}$ осуществлялось поочередное распыление мишеней высшего силицида марганца и ГДГ-0005. Толщина каждого слоя задавалась изменением времени распыления мишеней. В таблице приведен список структур с указанием технологических параметров формирования каждого слоя. Структуры отличаются относительными толщинами слоев.

Все структуры имеют одинаковую общую толщину нанесенной пленки (согласно оценкам, выполненным по времени распыления), но отличаются абсолютной толщиной слоев в ней и количеством периодов. Структура 1 представляет собой сравнительно однородный слой $\mathrm{MnSi}_{1.74}$, данная структура была сформирована для сравнения результатов.

После роста на поверхности исследуемых структур формировались омические золотосодержащие контакты методом электронно-лучевого осаждения в вакууме для последующего исследования коэффициента Зеебека. Формируемые контакты имели термическую стойкость в исследуемом диапазоне температур $\left(50-450^{\circ} \mathrm{C}\right)$.

\section{3. Методика эксперимента}

При измерении коэффициента Зеебека края образца помещались на два независимых нагревателя, температура которых задавалась и поддерживалась PIDтерморегуляторами. В процессе эксперимента между краями образца поддерживалась постоянная разность температур около $10 \mathrm{~K}$. Образец прижимался к нагревателям двумя молибденовыми прижимками (см. рис. 2), что было необходимо для улучшения теплового контакта между образцом и нагревателем. Молибден выбран вследствие малого значения коэффициента теплового расширения для предотвращения механического повреждения структуры при нагреве металла. Между образцом и прижимками устанавливались плоские термопары, выводы которых прикреплялись к термостатированной площадке в вакуумной камере. Напряжения регистрировались с термопар с помощью системы сбора данных L-Card E-140. Показания с термопар пропорциональны температурам на верхней грани исследуемой структуры. Напряжения, измеряемое с однотипных контактов („хромель-хромель“ $U_{\mathrm{Ch}}$, „алюмельалюмель“ $\left.U_{\mathrm{Al}}\right)$, пропорциональны возникающей термоЭДС с учетом термоэлектрического эффекта хромели $\alpha_{\mathrm{Ch}}$ и алюмели $\alpha_{\mathrm{Al}}$. Коэффициент Зеебека структуры: $\alpha_{s}=\alpha_{\mathrm{Ch}}+U_{\mathrm{Al}}\left(\alpha_{\mathrm{Ch}}-\alpha_{\mathrm{Al}}\right) /\left(U_{\mathrm{Al}}-U_{\mathrm{Ch}}\right)$.

Главным преимуществом описанной выше методики является отсутствие необходимости измерения истинной величины разности температур - коэффициент Зеебека структуры определяется путем сравнения возникающей термоЭДС относительно хромели и алюмели. Средняя температура вычислялась по формуле: $T=\left(T_{\text {hot }}+T_{\text {cold }}\right) / 2$, где $T_{\text {hot }}$ и $T_{\text {cold }}-$ температуры первого и второго столиков соответственно (см. рис. 2 ). 


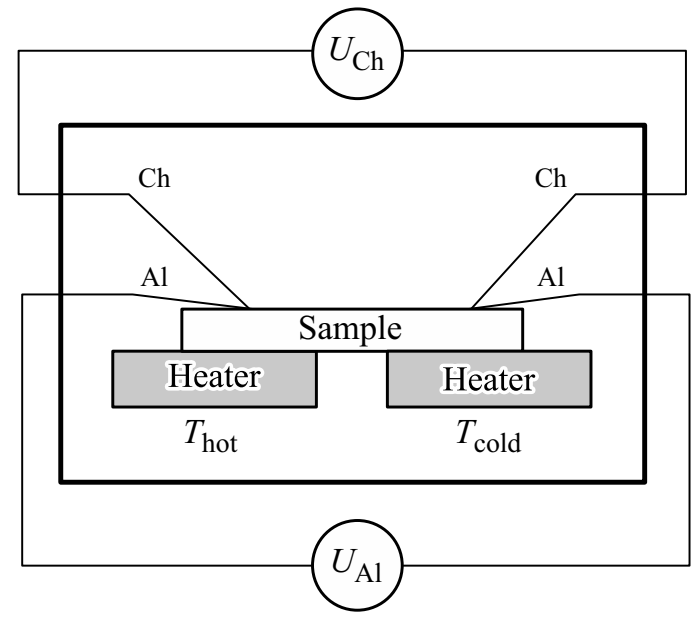

Рис. 2. Принципиальная схема измерения коэффициента Зеебека: $\mathrm{Al}$ - алюмель, $\mathrm{Ch}$ - хромель, Heater - печки, Sample исследуемый образец, $U_{\mathrm{Al}}, U_{\mathrm{Ch}}-$ вольтметр, регистрирующий термоэдс с ветвей алюмели и хромели соответственно, $T_{\text {hot }}, T_{\text {cold }}$ - температуры „горячей“ и „холодной“ печек соответственно.

Величина удельного сопротивления образца измерялась с помощью стандартной четырехзондовой схемы.

Величина коэффициента теплопроводности измерялась методом частотного разделения (3 $\omega$-метод) $[13,14]$. В ходе измерений сопротивления и коэффициента теплопроводности обеспечивалась нулевая разность температур между гранями образца.

Все измерения проводились в вакууме с давлением остаточных паров $10^{-3}$ Торр для уменьшения отвода воздушной средой тепла от нагретых областей образца и снижения деградации образца в результате воздействия атмосферы.

В результате исследований проводился анализ температурных зависимостей коэффициента Зеебека, удельного сопротивления, коэффициента теплопроводности и термоэлектрической добротности сформированных структур.

\section{4. Результаты эксперимента}

Из полученных температурных зависимостей коэффициента теплопроводности структур (рис. 3) видно, что, для одиночного слоя ВСМ величина $\lambda$ сопоставима с литературными данными [2]. При этом отметим, что для многослойной структуры коэффициент теплопроводности при температуре ниже $100^{\circ} \mathrm{C}$ выше, чем для одиночного слоя ВСМ, а при $T>100^{\circ} \mathrm{C}$ выше такового. Снижение коэффициента теплопроводности в многослойной структуре объясняется дополнительным фононным рассеянием на границе слоев $\mathrm{MnSi}_{1.74}$ и $\mathrm{Ge}$. При температурах ниже $100^{\circ} \mathrm{C}$ эффект рассеяния на границах нивелируется за счет более высокого значения коэффициента теплопроводности Ge [15-17] (вследствие чего усредненное по объему пленки значение $\lambda$, которое рассчитывается $3 \omega$-методом, становится выше). Однако при повышении температуры значение коэффициента теплопроводности Ge существенно снижается, и это приводит к уменьшению общего значения $\lambda$.

Из температурных зависимостей коэффициента удельного сопротивления (рис. 4) видно, что для всех структур, за исключением структуры 4, характерны близкие значения $\rho$. Самым низким сопротивлением обладает структура 1 (кривая 1), представляющая собой толстый одиночный слой ВСМ. Наличие промежуточного слоя германия приводит к увеличению сопротивления во всех рассмотренных случаях толщины. Повышение сопротивления в многослойных структурах можно объяснить взаимной диффузией атомов германия $\mathrm{Si}$ и $\mathrm{Mn}$. Предположительно, взаимная диффузия приводит к появлению дополнительных фаз в пленке (например, GeMn), что со-

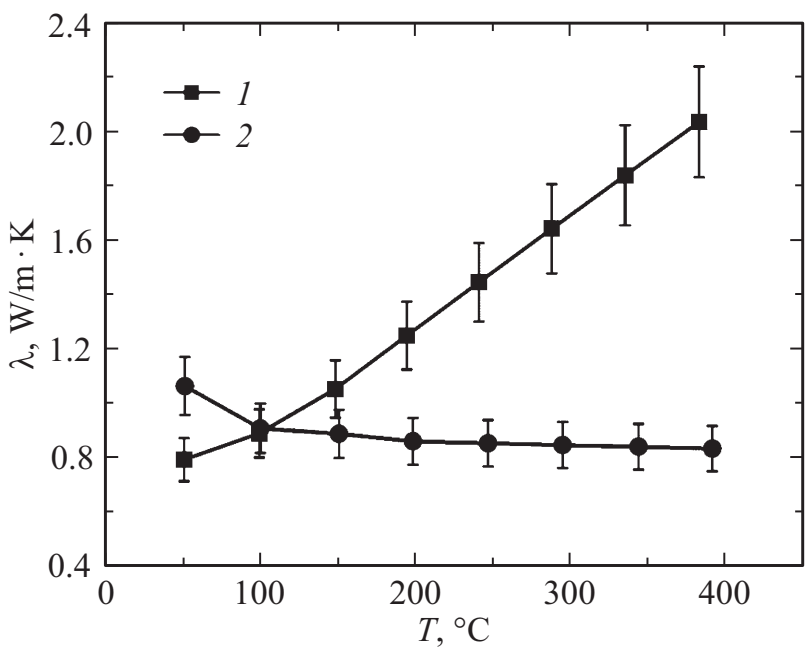

Рис. 3. Экспериментально полученная температурная зависимость коэффициента теплопроводности: 1 - одиночного слоя ВСМ, 2 - сверхрешетки на основе ВСМ и германия.

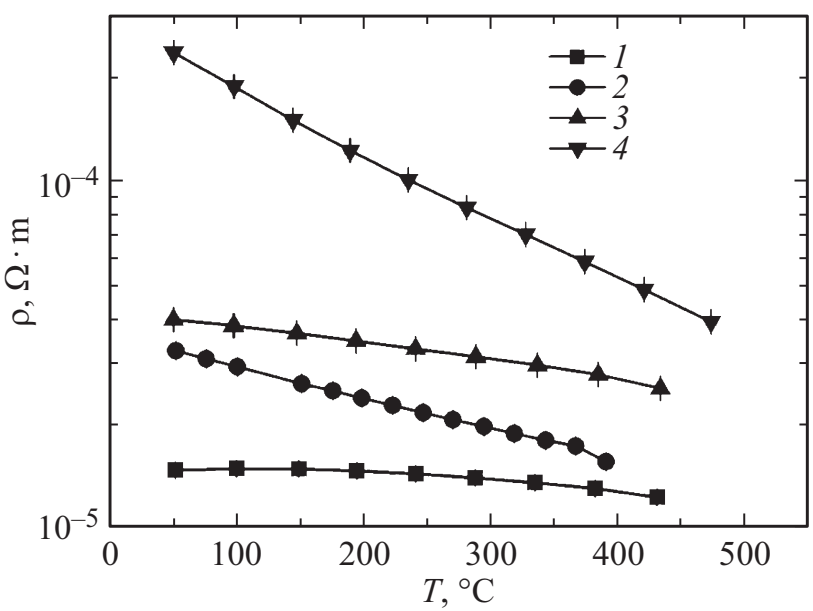

Рис. 4. Экспериментально полученная температурная зависимость коэффициента удельного сопротивления исследуемых структур: 1 - структура $1,2-$ структура $2,3,4-$ структуры 3 и 4 соответственно. 


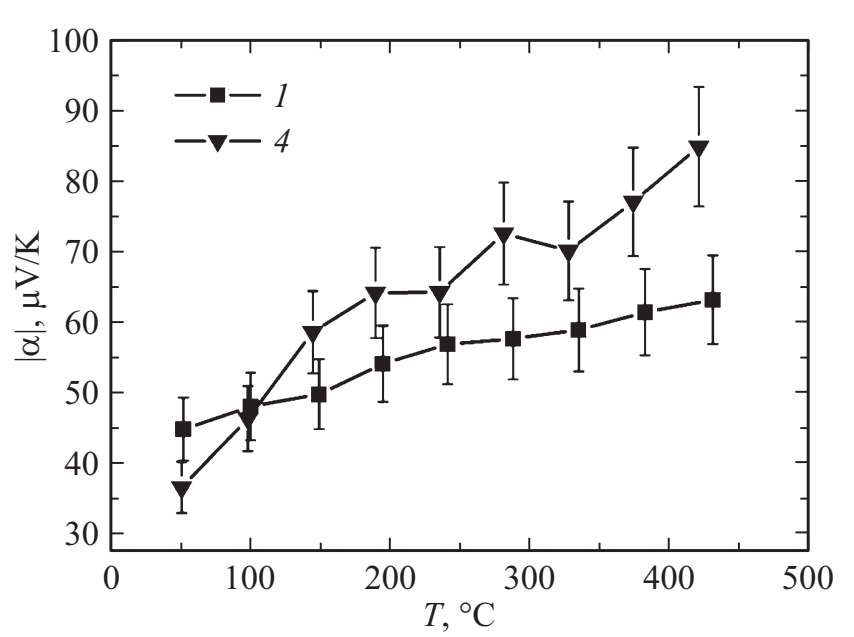

Рис. 5. Экспериментально полученная температурная зависимость коэффициента Зеебека исследуемых структур: 1 структура 4-структура 4.

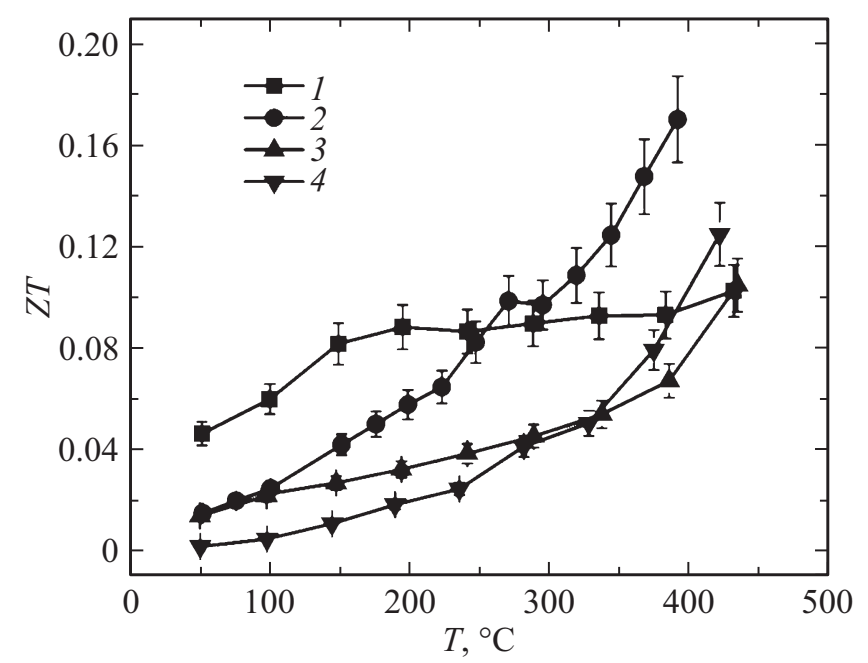

Рис. 6. Рассчитанная на основе полученных экспериментальных данных температурная зависимость термоэлектрической добротности исследуемых структур: 1 - структура $1,2-$ структура 2, 3, 4 - структуры 3 и 4 соответственно.

провождается возникновением внутренних потенциальных барьеров, препятствующих протеканию тока между слоями и увеличению электрического сопротивления нанесенной пленки. Наиболее ярко указанный эффект выражен для многослойной структуры с наименьшим периодом (структура 4 - кривая 4). В случае малой толщины каждого отдельного слоя потенциальные барьеры, возникающие вследствие появления новых фаз наиболее эффективно блокируют перенос тока по этому слою.

Температурная зависимость коэффициента Зеебека (рис. 5) структур 1-3 совпадает в пределах погрешности, поэтому на графике приведены кривые от структур 1 и 4. Анализируя температурную зависимость коэффициента Зеебека можно заключить, что величина эффекта коррелирует с величиной удельного сопротивле- ния. Таким образом, на структуре 4, обладающей самым высоким сопротивлением, было получено самое высокое значение термоэдс. Однако, термоэлектрическая эффективность этого слоя получилась худшей из представленных сверхрешеток. Наибольшее значение ZT (рис. 6) было получено на структуре 2 и составляет величину 0.18 , что сопоставимо с величинами, полученными в работе $[3,13-14,18,19]$.

Очевидно, повышение неоднородности пленки за счет введения слоев германия оказывает негативное влияние на токоперенос для всех исследованных структур. Повышение сопротивления сопровождается снижением величины ZT. В то же время негативное влияние $\mathrm{Ge}$ на электрические свойства полностью компенсируется снижением коэффициента теплопроводности в многослойных структурах. Для оптимального подбора толщин слоев это позволяет повысить коэффициент термоэлектрической добротности по сравнению с таковым для однородного слоя высшего силицида марганца.

\section{5. Заключение}

В работе рассмотрены термоэлектрические свойства тонкой пленок ВСМ, сформированных на сапфировой подложке методом ИЛО, а также сверхрешеток, состоящих из слоев ВСМ и промежуточных слоев германия. Экспериментально подтверждено, что введение промежуточных низкоомных слоев позволяет создать дополнительный объект рассеяния тепла в структуре границы раздела между слоями, что способствует снижению величины коэффициента теплопроводности при сохранении величины эффекта Зеебека.

Важно отметить, что в работе показана дополнительная технологическая степень свободы для управления термоэлектрическими параметрами сверхрешетки - за счет варьирования основного и промежуточного слоев. Это позволяет полностью компенсировать негативный эффект повышения сопротивления при введении слоев $\mathrm{Ge}$ и несколько повысить коэффициент $Z T$.

\section{Благодарности}

Авторы статьи выражают благодарность А.В. Борякову за исследование состава мишеней в растровом электронном микроскопе, М.С. Болдину за проведенные эксперименты по спеканию мишеней.

\section{Финансирование работы}

Работа выполнена при поддержке гранта РНФ (проект 17-79-20173).

\section{Конфликт интересов}

Авторы заявляют, что у них нет конфликта интересов. 


\section{Список литературы}

[1] J. Mahtashan. Energy Procedia 74 (2015).

[2] C. Gayner, K.K. Kar. Prog. Mater. Sci. 83, 330 (2016).

[3] Z.-G. Chen, G. Han, L. Yang, L. Cheng, J. Zou. Mater. Int. Progr. Natur. Sci. 22, 535 (2012).

[4] L. Ivanova. J. Thermoelectricity 3, 60 (2009).

[5] S. Saini, P. Mele, H. Honda, K. Matsumoto, K. Miyazaki, A. Ichinose. J. Electronic Mater. 43, 2145 (2014).

[6] M.V. Dorokhin, I.V. Erofeeva, Yu.M. Kuznetsov, M.S. Boldin, A.V. Boryakov, A.A. Popov, E.A. Lantsev, N.V. Sakharov, P.B. Demina, A.V. Zdoroveyshchev, V.N. Trushin. Nanosystem. Phys. Chem. Mathemat. 9, 622 (2018).

[7] S. Bathula, M. Jayasimhadri, N. Singh, A.K. Srivastava, J. Pulikkotil, A. Dhar, R.C. Budhani. Appl. Phys. Lett. 101, $213902(2012)$

[8] E. Witkoske, X. Wang, M. Lundstrom, V. Askarpour, J. Maassen. J. Appl. Phys. 122, 175102 (2017).

[9] И.А. Томбасов. ФТТ 60, 12 (2018).

[10] Y. Chandel. IJSR 4, 6 (2015).

[11] A. Kandemir, A. Ozden, T. Cagin, C. Sevik. STAM 18, 187 (2017).

[12] M.V. Dorokhin, I.V. Erofeeva, Yu.M. Kuznetsov, M.S. Boldin, V.P. Lesnikov, A.V. Boryakov, A.A. Popov, E.A. Lantsev, N.V. Sakharov, P.B. Demina, A.V. Zdoroveyshchev, V.N. Trushin. Nanosystems. Phys. Chem. Mathemat. 9, 622 (2018).

[13] K.T. Wojciechowski, R. Zybala, R. Mania. J. Achievements Mater. Manufacturing Eng. 37, 2 (2009).

[14] D. Cahill. Rev. Sci. Insrum. 61, 802 (1990).

[15] F. Schaffler, E. Levinshtein, S. Rumyantsev, M. Shur. Prop. Adv. Semicond. Mater: GaN, AIN, InN, BN, SiC, SiGe. Wiley, N.Y. (2001). 216 p.

[16] F. Schäffler. Semicond. Sci. Technol. 12, 1515 (1997).

[17] H. Stöhr, W. Klemm. Z. Anorg. Allgem. Chem. 241, 305 (1939).

[18] X. Chen, A. Weathers, A. Moore, J. Zhou, L. Shi. J. Electron. Mater. 41, 6 (2012).

[19] S. Joo, H. Lee, J. Lee, J. Jang. J. Alloys Comp. 747, 1 (2018).

Редактор Д.В. Жуманов 